Journal of Advanced College of Engineering and Management, Vol. 4, 2018

\title{
MICROSTRIP COMPACT TWIN-INTERDIGITAL STEPED IMPEDANCE RESONATOR-BASED BANDPASS FILTER FOR C-BAND APPLICATIONS
}

\author{
Ram Krishna Maharjan
}

Professor, Department of Electronics and Computer Engineering, Pulchowk Campus, T.U.

\begin{abstract}
This research focuses a new microstrip twin- interdigital type bandpass filter based on stepped impedance resonator (SIR) structure. The proposed structure consists of two slightly different interdigital capacitances within a single SIR resonator that behaves as a bandpass filter (BPF) of center frequency $4.3 \mathrm{GHz}$ with $700 \mathrm{MHz}$ bandwidth at $3 \mathrm{~dB}$ pass band. This design is not only subjected to size reduction, but also low pass-band insertion loss and high return loss as well. The Sonnet software tool has been used to design and simulate the microstrip BPF. The fabricated BPF was measured using the Agilent $8510 \mathrm{C}$ vector network analyzer (VNA) and achieved the insertion loss of $0.5 \mathrm{~dB}$ and the return loss of $26 \mathrm{~dB}$. The measured results were compared with those simulated results which were very close to each other. The fabricated BPF can be used for Cband Applications.
\end{abstract}

Keywords: Microstrip resonator; Interdigital capacitor; Bandpass filter; SIR resonator; Microstrip filter; C-band communications.

\section{Background}

In wireless communication world, nowadays the size reduction of the RF front-ends, and especially of RF filters, is still a great challenge. The bandpass filter is an essential component, which is usually used in both receiver and transmitter sections in microwave communication systems. Thus, the quality of bandpass filers is extremely important. Microstrip filters are currently the popular structures because they can be fabricated using printed circuit technology and are suitable for commercial applications due to their small size and lower fabrication cost [ 1,2 ]. Therefore, how to design a bandpass filter at low cost and with high performance is currently of great interest [4]. Microstrip bandpass filters can be easily mounted on a dielectric substrate and can provide a more flexible design of the circuit layout [3]. The dual-mode resonator filters have been known for years. The compact high performance microwave bandpass filters are highly desirable in the satellite communication systems as well. Consequently, the dual-mode BPFs have been used widely for the system because of their advantages such as small size, light weight, low loss and high selectivity [5]. Some of papers [57] have proposed the wide-band bandpass filters using dual-mode ring resonators with tuning stubs but the configurations still occupy a large circuit area, which is not suitable for wireless communication systems where the miniaturization is an important factor [4]. Therefore, it is desirable to develop new types of dual-mode microstrip resonators not only for offering alternative designs, but also for miniaturizing filters [6]. On the other hand, the modern wireless communication systems require the bandpass filters having effective out-of-band spurious rejection and good in-band performance. The microstrip open-loop resonators have a wide stop band resulting from the dispersion effect and the slow-wave effect [7-8].

In this research, a dual-mode bandpass filter using the microstrip twin-interdigital capacitive coupling quarter-wave resonators with SIR based structure is proposed. The bandpass filter is based on the bandstop phenomenon in undesired bands employing two dissimilar interdigital resonators are parallel direct-connected as a single microstrip structure [10-13]. The design and simulation of the microstrip bandpass filter are described in Section 2 and 3 respectively. The brief fabrication process and verification of the simulated results with experimental by using Vector Network Analyzer (VNA) are 
discussed in the Section 4. The overall research, development and achievements of this research work are concluded in Section 5.

\section{Design Methodology}

The microstrip interdigital filter consists of quarter-wave resonators which are coupled to each other and due to resonance characteristic behaviors only certain band of frequencies are allowed to pass whereas the rest of undesired bands are rejected. Microstrip resonator based bandpass filters themselves have gained popularity due to compact size, low cost, less weight, fabrication simplicity, compatibility, and find extensive applications in low-power to medium-power RF transceivers $[9,10$, 12-13]. The proposed BPF is targeted to apply in C-band applications. The two asymmetrical interdigital capacitances were tied up in parallel on the base of a SIR resonator. Due to the cancellation of capacitive and inductive reactance in the quarter-wave resonators, it began to resonate at $4.3 \mathrm{GHz}$ frequency. The pass band lower frequency and higher frequencies are 3.9 and $4.6 \mathrm{GHz}$ with $700 \mathrm{MHz}$ usable bandwidth. The designed BPF was fabricated on Teflon substrate with dielectric constant, $\varepsilon_{\mathrm{r}}$ of 2.52 and thickness of $0.54 \mathrm{~mm}$. The overall physical size of the fabricated BPF is 12.4 $\mathrm{mm}$ in width and $25 \mathrm{~mm}$ in length. At the centre frequency of $4.3 \mathrm{GHz}$, the fabricated BPF filter has a $3 \mathrm{~dB}$ fractional bandwidth of $16.3 \%$ approximately. The observed differences between simulations and measurements can be attributed to the unexpected tolerance of fabrication. The conductor loss, dielectric loss and non ideal microstrip coaxial line transitions contribute to the higher insertion loss in the measurement than that in the simulation [13]. The design sequences and simulations were accomplished using a Sonnet Suites electromagnetic (EM) simulator. The insertion loss, $\mathrm{S}_{21}$ is measured $0.65 \mathrm{~dB}$ return loss, $\mathrm{S}_{11}$ is observed $26.03 \mathrm{~dB}$ at the center operating frequency, $4.3 \mathrm{GHz}$.

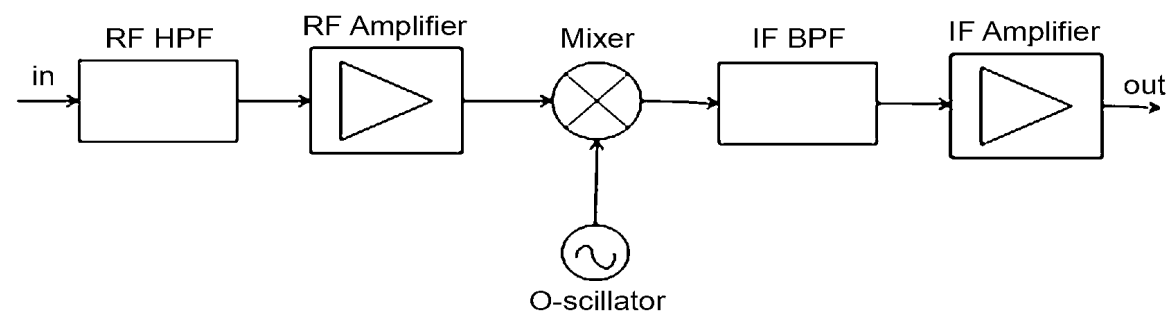

Fig. 1: Functional block diagram of down converter in RF receiving chain

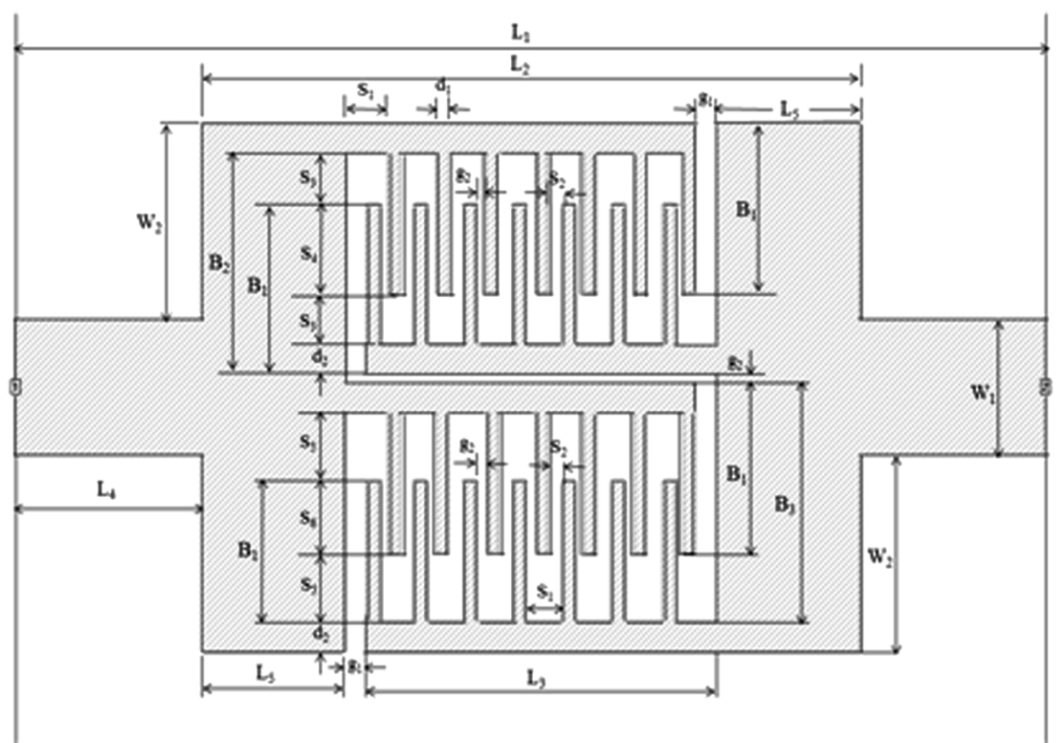

Fig. 2: Schematic of compact microstrip twin-interdigital bandpass filter 


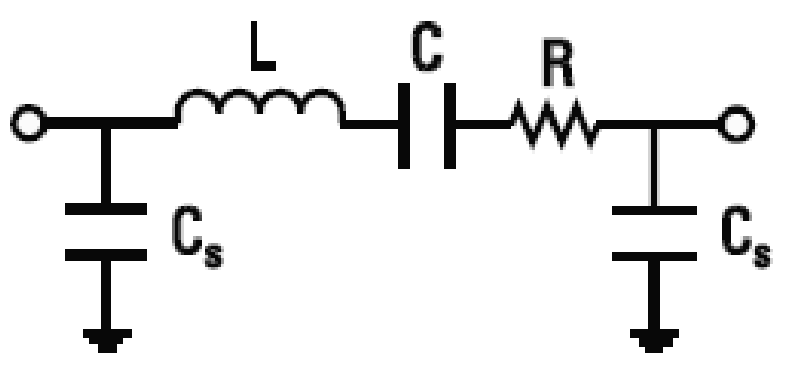

Fig. 3: An equivalent circuit of the microstrip twin-interdigital bandpass filter

The proposed BPF can be employed in the down converter of RF receiving. The filter was intended to equip a C-band receiver aboard or a ground Earth station for the satellite communications systems. Fig. 1 depicts the schematic of the receiver and shows the location of the IF filter on the downlink section. In a C-band receiver RF and IF frequencies are being used around 6 and $4 \mathrm{GHz}$ respectively. The IF BPF filter is used to limit passing only the intermodulation products appearing at its output of the RF signal as $6 \mathrm{GHz}$ minus LO signal $2.225 \mathrm{GHz}$.

As shown in Fig. 2, the twin-interdigital BPF designed structure, major dimensions were depicted. An equivalent circuit of the microstrip twin-interdigital bandpass filter was shown in Fig. 3. It consists of an RLC network. In this model, the $\mathrm{L}$ and $\mathrm{C}$ circuit components were used in order to get the resonant characteristics their reactance are equal and cancelled each other at resonance condition and the $\mathrm{R}$ is considered for the evaluation of the radiation effect and losses.

\section{The SONNET Simulations}

The current distributions of the dual-mode BPF in the different operating frequencies were illustrated in the Fig 4. It presented current density while the current distributed in microstrip twin-interdigital $\mathrm{BPF}$ at (a) $3.8 \mathrm{GHz}$, (b) $4.0 \mathrm{GHz}$, (c) $4.3 \mathrm{GHz}$, (d) $4.8 \mathrm{GHz}$ frequencies. It has shown the current distribution phenomena of the designed structure using the EM simulation tool at mainly given four frequencies. The Figure 4 (c) has also shown the equal and well current density at $4.3 \mathrm{GHz}$ resonant frequency while others are different each others. The research sequences and required simulations were accomplished using a Sonnet Suites electromagnetic simulator [14].
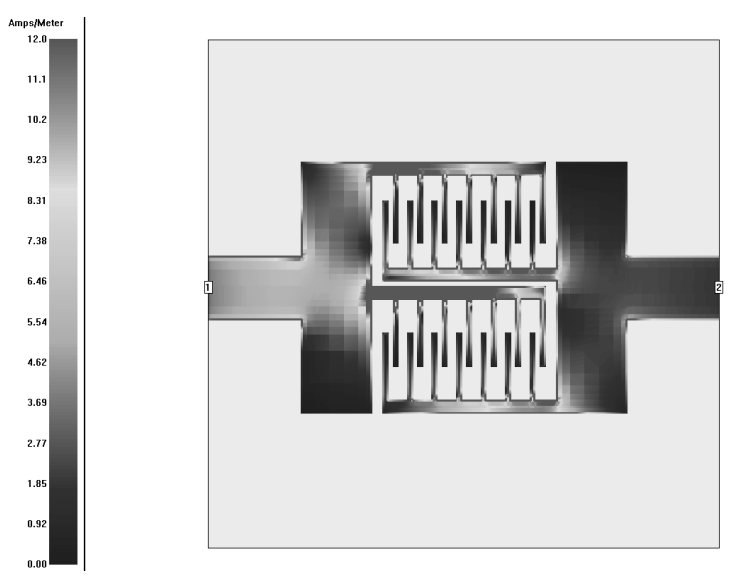

( a )
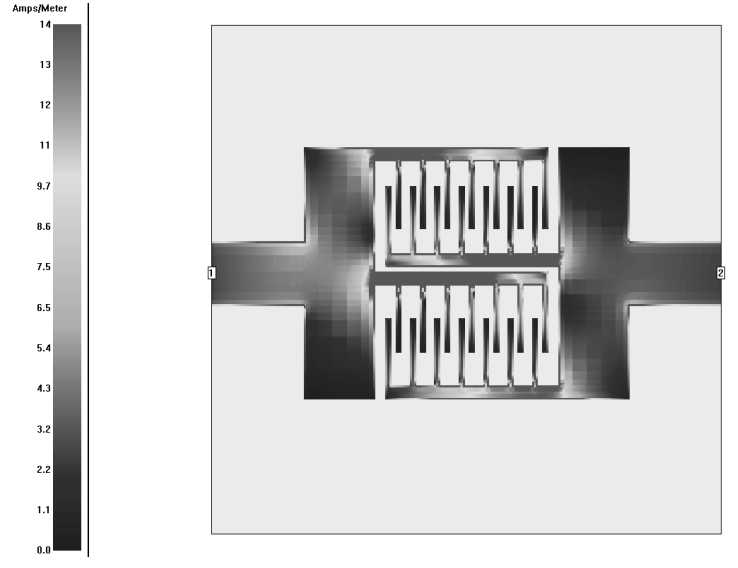

(b) 

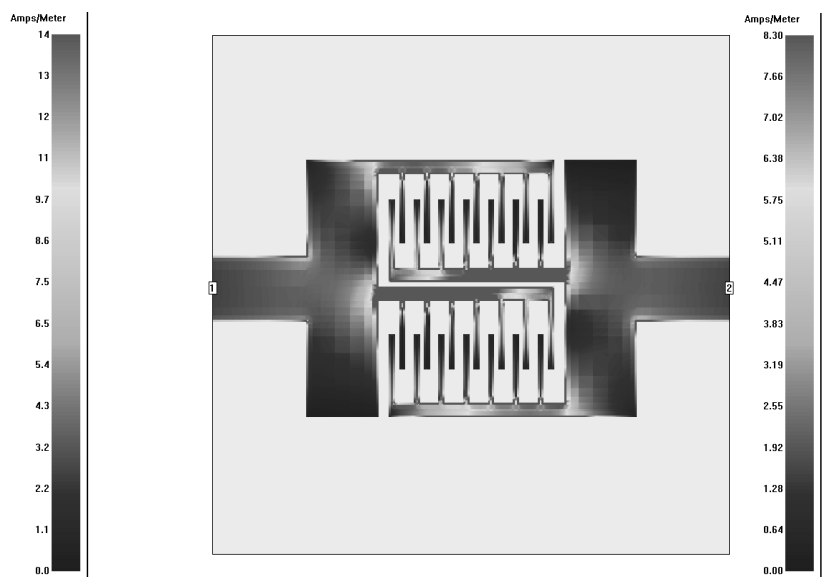

(c)

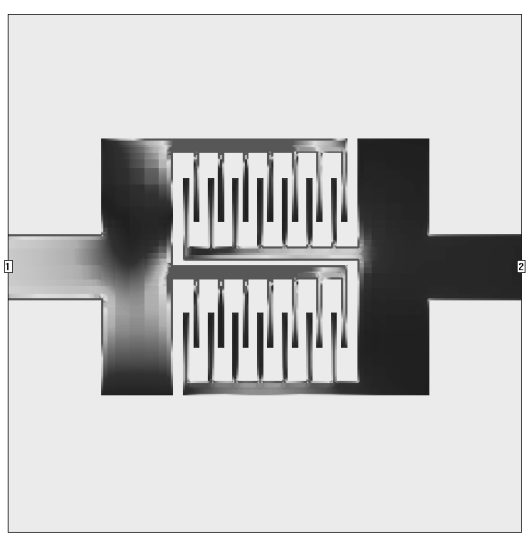

( d )

Fig. 4: Current distributions in microstrip twin-interdigital BPF at (a) $3.8 \mathrm{GHz}$,(b) $4.0 \mathrm{GHz}$, (c) 4.3 $\mathrm{GHz},(\mathrm{d}) 4.8 \mathrm{GHz}$ frequencies

\section{4. $\quad$ Fabrication and Measured Results}

To confirm the simulated results, we had accomplished fabrication of the proposed bandpass filter on the Teflon substrate with dielectric constant, $\varepsilon_{\mathrm{r}}$ of 2.52 and thickness of $0.54 \mathrm{~mm}$. The overall physical size of the fabricated BPF is an area of $1.24 \mathrm{~cm} \times 2.5 \mathrm{~cm}$. As following the preceding design process, the dimensions which are shown in Fig. 2 are obtained as follows: $\mathrm{L}_{1}=25 \mathrm{~mm}, \mathrm{~L}_{2}=16.4 \mathrm{~mm}, \mathrm{~L}_{3}=$ $9.1 \mathrm{~mm}, \mathrm{~L}_{4}=4.3 \mathrm{~mm}, \mathrm{~L}_{5}=3.4 \mathrm{~mm}, \mathrm{~W}_{1}=3.2 \mathrm{~mm}, \mathrm{~W}_{2}=4.6 \mathrm{~mm}, \mathrm{~B}_{1}=4 \mathrm{~mm}, \mathrm{~B}_{2}=5.2 \mathrm{~mm}, \mathrm{~B}_{3}=$ $5.6 \mathrm{~mm}, \mathrm{~S}_{1}=0.9 \mathrm{~mm}, \mathrm{~S}_{2}=0.5 \mathrm{~mm}, \mathrm{~S}_{3}=1.2 \mathrm{~mm}, \mathrm{~S}_{4}=2.1 \mathrm{~mm}, \mathrm{~S}_{5}=1.6 \mathrm{~mm}, \mathrm{~S}_{6}=1.7 \mathrm{~mm}, \mathrm{~d}_{1}=$ $25 \mathrm{~mm}, \mathrm{~d}_{2}=25 \mathrm{~mm}, \mathrm{~g}_{1}=0.5 \mathrm{~mm}, \mathrm{~g}_{2}=0.2 \mathrm{~mm}$. Because of the unavoidable presence of fabrication tolerance, it is necessary to analyze the sensitivity [2, 4, 5, 11-13]. In this BPF, the performance of the pass bands is affected by the coupling between interdigital resonators 1 and 2. Furthermore, the coupling gap, $\mathrm{g}_{1}$ and $\mathrm{g}_{2}$ are narrow and thus it is more sensitive to fabrication errors than other parameters remarkably. Therefore, the gap is chosen to perform the sensitivity analysis. It undergoes random errors of $16.7 \%$, or $0.05 \mathrm{~mm}$, which is usually the maximum fabrication error in Teflon substrate based microstrip.

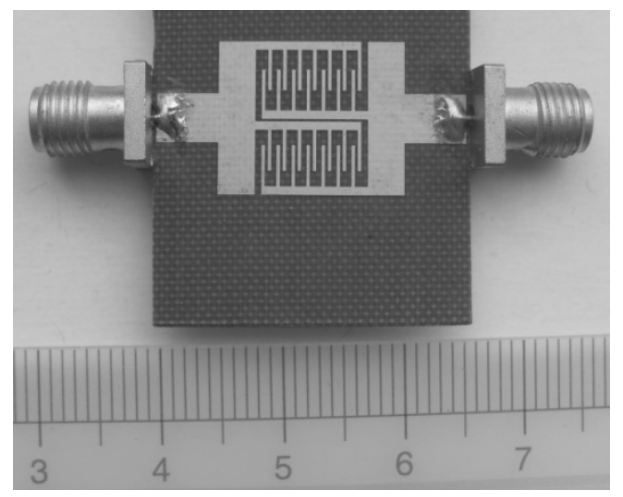

Fig. 5: Photograph of a fabricated twin-interdigital Bandpass Filter 


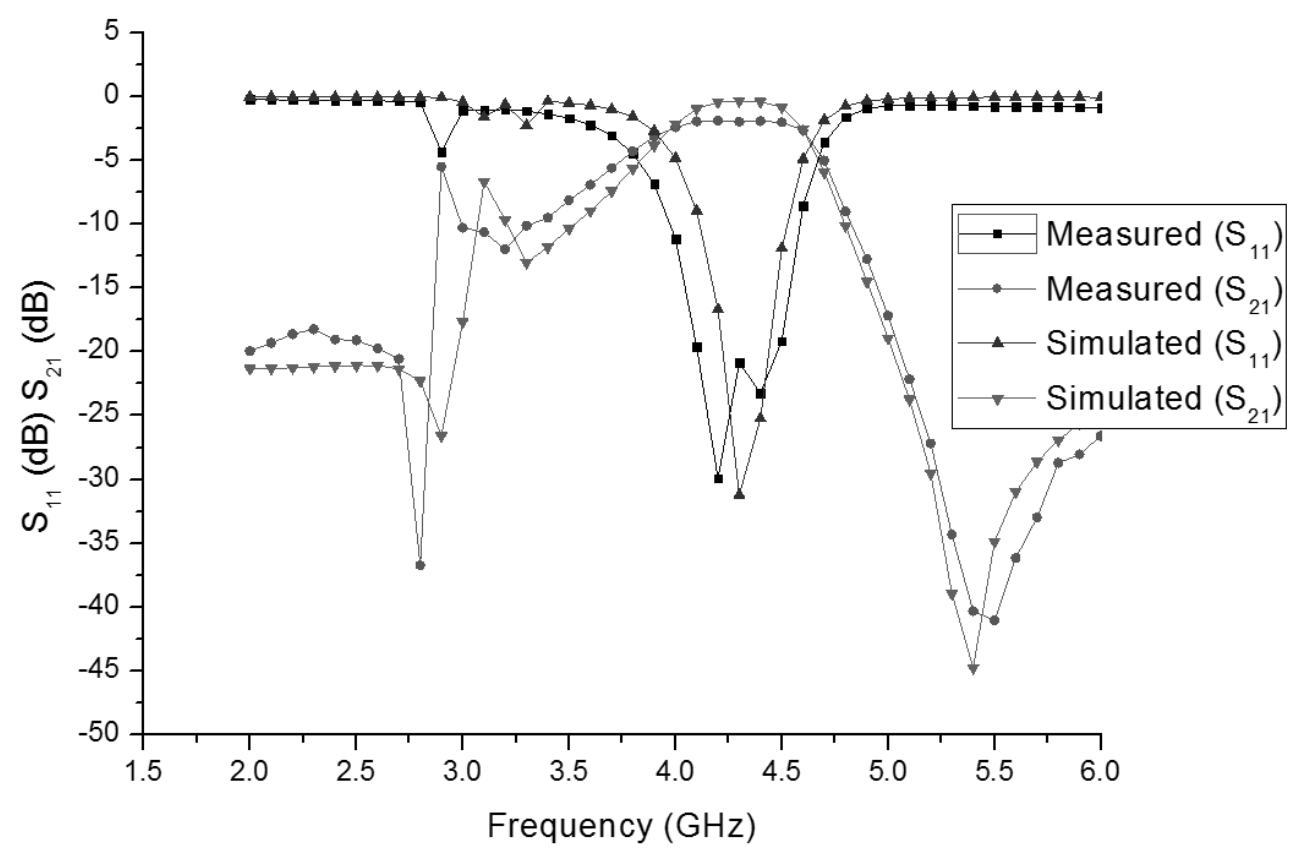

Fig. 6: Simulated and measured frequency responses of the proposed twin-interdigital Bandpass Filter The photograph of the proposed fabricated twin-interdigital BPF is demonstrated in Fig.5. The fabricated BPF was measured using the Agilent $8510 \mathrm{C}$ vector network analyzer (VNA). The minimum insertion loss was measured and achieved to be less than $0.5 \mathrm{~dB}$. The return loss within the passband is greater than $26 \mathrm{~dB}$. The measured results were compared with the simulated results especially in S-parameters, $S_{11}$ and $S_{21}$ is shown in Fig. 6.

\section{Conclusion}

This paper has proposed a twin-interdigital bandpass filter using a microstrip asymmetrical SIR on a novel structure concept. The quarter-wave resonance effects in the interdigital arms have been coupled to each other and due to resonance characteristic behaviors; this designed has been successfully demonstrated. The measured results of the filter design responses agree very well with the simulated expectations. Both simulated and measured results have demonstrated; they are almost identical in an electrical performances and specifications. The better performance, planar structure, low cost and compact size make it attractive for $\mathrm{C}$-band satellite communication applications.

\section{Acknowledgment}

This research was supported by the National Research Foundation of Korea (NRF), andGrants from the Korean Government (MEST) No.2012-0009224 and IPD Project No. 2012R1A1A2004366. This work was also supported by a Research Grant from Kwangwoon University, Seoul in 2008-2012 during my $\mathrm{PhD}$ research period.

\section{References}

1. Makimoto, M. and Yamashita, S., "Microwave Resonators and Filters for Wireless Communication Theory”, Application, Springer, Berlin, Chaps. 2 - 4, (2001)

2. Pozar, D. M., “Microwave Engineering”, $3^{\text {rd }}$ edition, New York, Wiley Publications, (2001) 
3. Maharjan, R. K.andKim, N. Y.,"Microstrip even-mode half-wavelength SIR based I-band interdigital bandpass filter", Indian Journal of Engineering and Materials Science(IJEMS),ISSN:0971-4588, NISCAIR,India,Vol.19, No. 5, pp. 299-303, (2012)

4. Zhurbenko, V., "Passive Microwave Components and Antennas", In-Tec Publication, Olanjnica, Croatia, (2010).

5. Hsieh, L. H. and Chang, K. "Compact, Low Insertion-loss, Sharp-rejection Wideband Bandpass Filters using Dual-mode Ring Resonators with Tuning Stubs”, Microwave and Optical Technology Letters, Vol.45, No.4, 312-315, (2001)

6. Maharjan, R. K., Shrestha, B. and Kim, N. Y., "Microstrip symmetrical twin-spiral inductor resonator filter for UWB applications", The Arabian Journal for Science and Engineering (AJSE), ISSN:1319-8025, Springer's Publication, SA, Vol. 38, No. 9, 2465-2472, (2013)

7. M.H. Weng, H.W. Wu, and C.Y. Hung, "A Compact Pseudo-Interdigital SIR Bandpass Filter with Improved Stopband Performance", Microwave and Optical Technology Letters, Vol.47, No.5, 462-464,(2005)

8. Maharjan, R. K. and Kim, N. Y., "Compact stub-coupled square open-loop band pass filter for Ku-band applications", Journal of Electromagnetic Wave sand Applications (JEMWA),ISSN:0920-5071, Taylor \& Fransis Publication, The United Kingdom (UK), Vol.26, No. 5-6, 603-614, (2012)

9. Z.H. Bao, Z. H., Chen, J.X. Chen, Tang, H. and L.H. Zhou, "Compact Dual-band Bandpass Filter using Slot-line Resonator", Microwave and Optical Technology Letters, Vol.52, No.10, 2299-2300, (2010)

10. Maharjan, R. K. and Kim, N. Y., "Microstrip dual I-band bandpass filter with symmetrical twin-inductor resonators", Microwave and Optical Technology Letters (MOTL),ISSN:08952477, Wiley Publishers, USA,Vol.54, No.3, 638-641, (2012)

11. Maharjan, R. K., Shrestha, B. and Kim, N. Y.,"Compact microstrip square open-loop band pass filter using open stub”,Electronic Letters, ISSN: 0013-5194, IET Publication, UK, Vol.48, No.6, 333-334, (2012)

12. Maharjan, R. K. and Kim, N. Y.,"Miniature stubs-loaded square open-loop band pass filter with asymmetrical feeders", Microwave and Optical Technology Letters(MOTL),ISSN:08952477, Wiley Publishers, USA,Vol.55, No. 2, 329-332, (2013)

13. Maharjan, R. K. and Kim, N. Y., "Microstrip bandpass filters using window hairpin resonator and T- feeder coupling line,", The Arabian Journal for Science and Engineering (AJSE),ISSN:13198025, Springer's Publication, SA, Vol.39, No. 5, 3989-3997, (2014)

14. Sonnet Suites 12 ver., "User's Guide", Sonnet Software, Inc., North Syracuse, NY13212, USA, (2010) 